\title{
Research on Current Situation of Agricultural Products Online Sales Standards in Hubei Province
}

\author{
Ying Liu \\ Economic College \\ Wuhan Donghu University \\ Wuhan, China \\ helen1982117@sina.com
}

\author{
Lingzhi Liu \\ Economic College \\ Wuhan Donghu University \\ Wuhan, China \\ 2528085972@qq.com
}

\begin{abstract}
To clarify the status quo of agricultural products online sales, to promote the development of agricultural products online sales activities, from the marketable perspective, agricultural products are subdivided into agricultural products quality grading and classification standards, the standards of postpartum commercial treatment and distribution of agricultural products. After field research, task group find out the status quo of agricultural products in Hubei Province, so as to provide a useful reference for the government and related institutions in Hubei province.
\end{abstract}

Keywords-Agricultural products; Online sales standards; Current situation

\section{INTRODUCTION}

In recent years, the rapid development of agricultural e-commerce has become an important manifestation of the development of agricultural modernization and information. The next 3-5 years will be the explosive growth era of agricultural products e-commerce. Hubei, as a traditional agricultural Province, should take the momentum, seize the chance, give full play to the advantages, and actively promote efficient breakthrough development of agricultural e-commerce to play a strong supporting role for speeding up the construction of big agricultural province.

At present, the low degree of standardization of agricultural products has become an important factor hindering the development of agricultural e-commerce. Because of the wide variety of agricultural products, the complex and diverse index of reflecting products, the actual situation of the difficulty in formulating and unifying the standards of agricultural products, From the marketable angle of agricultural products trading online, agricultural products are normatively refined into three standards: agricultural products quality grading and classification standards, the standards of postpartum commercial treatment (including packaging specifications and product codes standard)and distribution of agricultural products., collect the relevant standards from government departments, trade associations, agricultural enterprises and e-commerce services agency, and especially trying to clarify the developmental status of standards for online sales of agricultural products in Hubei Province, with a view to being helpful to boost the development of Internet marketing of agricultural products e-commerce. 


\section{Current Situation of the Development of Agricultural Products Online Sales in Hubei Province}

2.1 Current situation of agricultural products quality and classification standard in Hubei Province

So far, to ensure the quality and safety of agricultural products in Hubei Province, and to establish agricultural product quality standard system, Hubei Province has introduced some laws, regulations and policies that have important standards under the guidance of relevant State laws and regulations. In the November 2008 Hubei Province implemented the policy <People's Republic of China agricultural products quality security law>, this policy respectively makes main specification on the origin of agricultural products, inputs, agricultural production and management etc., and takes detail supervision and legal responsibility norm on the implementation of quality and safety inspection and supervision. Then in August 2009 Office of the Hubei Provincial Government has promulgated <the notice on matters related to the implementation of the quality and safety market access system>, which implemented the market access system on divided time, variety and scope of diverse agricultural products, the province where regional wholesale markets, supermarkets and warehouse, distribution center, farmers ' markets sell fresh vegetables, pork, fruit, animal products and aquatic products, such as market access for all agricultural products marketing, must provide relevant documents, otherwise qualified sampling is necessary to go on sale. To further promote the development of agricultural industrialization and enhance the quality and safety and market competitiveness of agricultural products in Hubei Province, Agriculture Department of Hubei Province in 2011 formulated the <Guiding Opinions on accelerating the standardization of agricultural production>, which claims to fully aware of the important meaning of promoting standardization of agricultural products, build the three systems --agricultural standardization organization and management systems, technical standards and standardized production and demonstration ,in order to highlight implementing <non-pollution agricultural products action plan>, focus on agricultural production and management specialization, standardization, scale, intensive development, establish and improve the agricultural product standard system, increase efforts to promote agricultural standardization, strengthen agricultural product quality inspection and quality certification, vigorously develop green agriculture and brand agriculture, and actively carry out pollution-free agricultural products, green food, organic agricultural products and geographical indications protection agricultural products recognized certification, foster agriculture boutique brand, promote agricultural efficiency, farmers' incomes and comprehensive development of the rural economy in Hubei Province.

In accordance with the planning <guidelines on speeding up the standardization production of agricultural products>, around pollution-free agricultural products, the need for green food production and marketing of advanced agricultural products, agricultural product quality standard system construction in Hubei province have achieved significant progress. By the end of 2013, "three one" (including pollution-free agricultural products, green food, organic produce and geographical indications of agricultural products) had been effectively used by 1532 logo brand enterprises, total brands reached 4295 , total output reached 18.85 million tons, the gross annual value reached $¥ 63.8$ billion, the sampling qualified rate reached $99.3 \%$, the total size continued to maintain the forefront of the 
nation. The implement on quality and safety of agricultural products is a starting point to standard system construction of agricultural products in Hubei Province, and actively combined with the latest scientific and technological achievements in Hubei, formulate the excellent and accordant with local actual production technical regulations and standard production, and encourage local government, agricultural enterprises or production base to develop agricultural production standards higher than national standards or industry standards, to further improve the agricultural products local standards of Hubei Province.

To further consolidate and enhance the standardization construction achievements of agricultural products in Hubei Province, local governments of Hubei also stepped up develop and modify the relevant technical standards for agricultural product quality, improve agricultural product quality standard system. To conclude, agricultural products technical quality standards of Hubei mainly includes the following aspects. The first is basic criteria such as <Wufeng tippy tea>(No. DB42 / T195-2000); The second is the production technical standards of agricultural products, such as <Technical specification for high-yield and efficient pollution-free production of high-quality medium gluten wheat $>$ (No. DB4205/T27-2006); The third is the standard of detection methods, such as the <local food safety standards in Hubei Province, monomethyl arsenic, dimethyl arsenic, arsenate and arsenitein aquatic products, HPLC - Atomic Fluorescence Spectrometry "(No. DBS42/003-2014); The fourth is management standards of agricultural products planting cultivation etc., such as <pollution-free food double spores mushroom growing media safety technical requirements $>$ (No. DB4205/T25-2006) and <pollution-free food double spores producing environmental
requirements>(No. DB4205/T24-2006).

2.2 Current situation of postnatal commodity related standards of agricultural products in Hubei Province

Postpartum commercialization treatment standard of agricultural products, which mainly refers to the production of agricultural products, in accordance with the needs of online sales, according to the characteristics of the product itself, packaging specifications, stencils coding standards. At present, Hubei province has been found to issue directly postpartum commercialization treatment standard of agricultural products, but the protection of geographical indications products has been carried out smoothly. Consumers can distinguish the product origin by product code, and can also by their geographical indication, which is extremely beneficial for online sales of agricultural product with the world-famous and the geographical characteristics. The relevant standard is document No. 78 <geographical indication protection regulations $>$ issued and implemented by Administration of Quality Supervision, Inspection and Quarantine since July 2005, which made detail specific provisions on application and approval procedures of geographical indication product protection.

Some of the characteristics of agricultural products in Hubei Province, as Caidian lotus root, Longfeng tea, Luotian chestnut, have qualified for the national geographical indication certification. After postpartum commercialization treatment of agricultural products, and obtaining geographical indications, these characteristics of agricultural products played an active role in the development of local economy, the increase of farmers' incomes and agricultural enhancement.

2.3 Current situation of agricultural product distribution standards in Hubei Province

Traffic location in Hubei has a unique 
advantage. Wuhan as the Center can form four levels of logistics services: 1hour, 6hours, 24hours and 72hours, radiating to the nation. Currently there are ten e-commerce platforms in our province to have set up regional headquarters or logistics distribution center. However, the relevant distribution criteria have not been established accordingly. Such as key development areas of agricultural product e-commerce in northwest of Hubei Province, the area is rich in agricultural resources, its landscape is dominated by mountains and hills. The region has rich soil, special terrain and good weather conditions, resulting in a variety of crops suitable for cultivation here. Abundant agricultural products meet people's daily lives in the Northwest of Hubei Province, at the same time, being used gradually as the large-scale supply of raw materials in industrial production; logistics distribution needs to strengthen in Hubei Province and the country. Special natural scenery in northwest Hubei cause inconvenience to local traffic, agricultural logistics development lags seriously hindered the development of agricultural product online sales in the Northwest of Hubei, became the bottleneck of the local economic development. Currently online sales and distribution in the region is mainly carried out by cold-chain logistics.

\section{Conclusions}

Hubei province should combine with online trading information platform and solid agricultural products information under the line, improve the standard system of demonstration products, increase agricultural product standards, strengthen the core demonstration area construction, and increase the distribution of network sales logistics resources, the implementation of intensive distribution. At the same time, optimize and improve the distribution network layout.

\section{Acknowledgement}

This paper was sponsored by Wuhan Donghu University. It is the staged achievements of two research subjects, which name are.The survey on agricultural products online sales standards in Hubei Province (The project of Hubei Provincial Collaborative Innovation Center Agricultural E-commerce (cultivation) in 2015) and Research on the innovation of agricultural science and technology communication system to cope with the changes of agricultural climate (Youth Fund Project of Wuhan Donghu University in 2014).

\section{References}

[1] Jin Zhenghua, Zhao Yajuan, Sun Yongqiang, and Yin Weiqian, "Talking about the development of agricultural e-commerce in Danyang city", China electronic business: technology innovation, December 2013, pp28.

[2] Xinhua, "Interpretation of agricultural product quality security law", Agricultural knowledge: scientific culture, November 2006, pp6-7.

[3] Zhang Kai, "Problems and countermeasures of quality certificate of agricultural production Nanyang city", Agriculture of Henan Province, 2012(5), pp22-23.

[4] Chiu pinrong, "Analysis on legal protection of geographical indications of agricultural products in China", Finance and Trade Research, October 2008, pp134-140. 